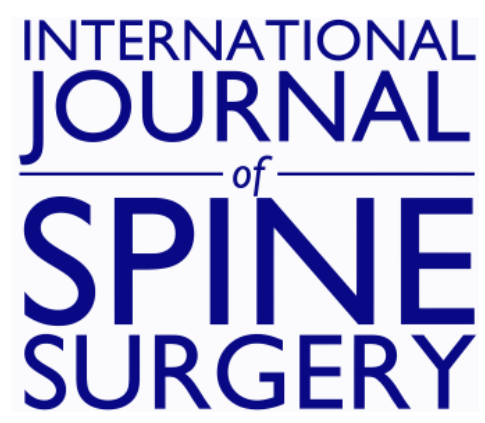

\title{
Current Concepts of Contemporary Expandable Lumbar Interbody Fusion Cage Designs, Part 1: An Editorial on Their Biomechanical Characteristics
}

Boyle C. Cheng, Isaac Swink, Rachelle Yusufbekov, Michele Birgelen, Lisa Ferrara, Kai-Uwe Lewandrowski and Domagoj Coric

Int J Spine Surg 2020, 14 (s3) S63-S67

doi: https://doi.org/10.14444/7128

http://ijssurgery.com/content/14/s3/S63

This information is current as of April 26, 2023.

Email Alerts Receive free email-alerts when new articles cite this article. Sign up at: http://ijssurgery.com/alerts 


\title{
Current Concepts of Contemporary Expandable Lumbar Interbody Fusion Cage Designs, Part 1: An Editorial on Their Biomechanical Characteristics
}

\author{
BOYLE C. CHENG, PHD, ${ }^{1}$ ISAAC SWINK, MS,${ }^{1}$ RACHELLE YUSUFBEKOV, BS, ${ }^{2}$ MICHELE BIRGELEN, \\ AS, ${ }^{1}$ LISA FERRARA, PHD, ${ }^{3}$ KAI-UWE LEWANDROWSKI, MD,${ }^{4}$ DOMAGOJ CORIC, MD $^{5,6}$ \\ ${ }^{1}$ Department of Neurosurgery, Allegheny Health Network, Pittsburgh, Pennsylvania, ${ }^{2}$ Integrity Implants Inc, Palm Beach Gardens, Florida, ${ }^{3}$ OrthoKinetic \\ Technologies LLC, Southport, North Carolina, ${ }^{4}$ Center for Advanced Spine Care of Southern Arizona and Surgical Institute of Tucson, Arizona, ${ }^{5}$ Carolina \\ Neurosurgery \& Spine Associates, Charlotte, North Carolina, ${ }^{6}$ Atrium Musculoskeletal Institute, Charlotte, North Carolina
}

\begin{abstract}
Background: Bidirectional expandable designs for lumbar interbody fusion cages are the latest iteration of expandable spacers employed to address some of the common problems inherent to static interbody fusion cages.

Objective: To describe the rationales for contemporary bidirectional, multimaterial expandable lumbar interbody fusion cage designs to achieve in situ expansion for maximum anterior column support while decreasing insertion size during minimal-access surgeries.

Methods: The authors summarize the current concepts behind expandable spinal fusion open architecture cage designs focusing on advanced minimally invasive spinal surgery techniques, such as endoscopy. A cage capable of bidirectional expansion in both height and width to address constrained surgical access problems was of particular interest to the authors while they analyzed the relationship between implant material stiffness and geometric design regarding the risk of subsidence and reduced graft loading.

Conclusions: Biomechanical advantages of new bidirectional, multimaterial expandable interbody fusion cages allow insertion through minimal surgical access and combine the advantages of proven device configurations and advanced material selection. The final construct stiffness is sufficient to provide immediate anterior column support while accommodating reduced sizes required for minimally invasive surgery applications.
\end{abstract}

Level of Evidence: 7.

Special Issue

Keywords: subsidence, stiffness, contact area

\section{INTRODUCTION}

Intervertebral fusion cages, often referred to only as interbody cages, are implantable devices that provide immediate anterior column support and distraction to a treated functional spinal unit (FSU) during interbody fusion surgery. During the last 2 decades, several forms of interbody fusion have become routinely employed for lumbar spinal pathologies, including posterior and transforaminal interbody fusion (TLIF), as well as anterior and lateral approaches. The posterior approaches, posterior interbody fusion/TLIF, remain most popular despite the anatomic hazards of placing the cage(s) in the relatively small working space between the exiting and traversing nerve roots, known as the Kambin triangle. ${ }^{1}$ An interbody cage's function is to maintain the desired intervertebral height until a bony union can form between the 2 vertebral bodies, which requires the device to provide biomechanical stability as the patient recovers and regains mobility.

Factors that influence an interbody construct's biomechanical stability include device geometry, stiffness, contact area, and the addition of integrated or supplemental fixation. An in vitro biomechanics study conducted in 1993 by Closkey et $\mathrm{al}^{2}$ established a contact area threshold of $25 \%$ or more end plate coverage to guard against subsidence risk. Achieving maximum end plate coverage is essential, even when used combined with supplemental pedicle screw fixation, because significant loads are still transferred through the disc space. ${ }^{3}$ The recent trend toward minimally invasive surgical (MIS) techniques due to the associated reductions in blood loss, morbidity, and improved cosmetic outcomes makes achieving maximum end plate coverage more 
difficult. $^{4-6}$ As a result, expandable interbody cage devices have gained popularity in recent years.

\section{ADVANTAGES OF EXPANDABLES}

Expandable cages are advantageous for 2 significant reasons: (1) anterior column support tailored to the specific interbody space and (2) providing the necessary surgical access to deliver interbody stabilization devices with sufficient height, lordosis, and end plate coverage while minimizing dural and neural retraction. Marketed expandable devices accomplish these goals with varying levels of success. Currently, the most popular expandable devices have an integrated mechanism that allows for the adjustment of height, that is, uniplanar expansion in the cephalad-caudal plane. ${ }^{6-9}$ If the device's design was also able to increase end plate coverage, the optimized design would potentially decrease the risk of subsidence. The device's design goal would fulfill the clinical necessity for immediate stabilization via the implant until arthrodesis can be achieved. The surgeons' perspective on expandable interbody fusion cages have been highlighted in another editorial article in this supplemental focus issue of the International Journal of Spine Surgery (IJSS).

Many parameters have been suggested as clinically relevant indicators of spinal stability. Range of motion (ROM) is the most commonly used metric with utility in both the clinical and biomechanical setting. For in vivo comparisons of stability (e.g., between degenerative conditions and fused spines), ROM may be readily determined but may not be sufficient in characterizing the efficacy of a given spinal device. A relevant example would be the response seen between 2 similar fixation strategies, such as unilateral and bilateral pedicle screw constructs. Few cadaveric biomechanical studies that have relied on ROM as a lone metric have been able to consistently differentiate the effect on the implanted cadaveric FSU between unilateral and bilateral constructs. ${ }^{7}$ Parameters such as the stiffness of an FSU, which incorporate vertebral displacement as a function of load, which offers both physical relevance and a direct-controlled correlation to stability, should be considered a means of comparison between constructs.

The displacement data generated from in vitro spine biomechanics experiments are often presented as a hysteresis loop, which are plots of applied load versus recorded displacement. A great deal of information can be gathered from these loaddisplacement plots, including ROM, stiffness, energy loss, and other factors, such as the neutral zone (the region in which a small load produces a massive displacement). Parameters previously used to measure stability include the area bounded by the hysteresis loop (energy loss) and average slope over specific regions or the entire hysteresis loop (stiffness). The hysteresis loop area is the energy dissipated by the specimen during a cycle of loading. ${ }^{8}$ This parameter has been of interest because of its physical meaning and the potential to incorporate design attributes akin to native tissue characteristics in stabilization devices. Constructs that can dissipate more energy (an increased area bounded by the hysteresis loop) are more viscoelastic, such as a healthy intervertebral disc. ${ }^{9}$ A clear correlation with spinal stability has not been shown through kinematics testing in the literature (e.g., neutral zone stiffness). ${ }^{10-16}$

\section{CONSTRUCT STIFFNESS}

Material stiffness is a fundamental material property derived empirically from homogenous isotropic test coupons. The same material configured in the form of a spinal implant has a different construct stiffness compared with the native material, that is, a construct stiffness that is a function of the implant geometry and the intrinsic native material properties. One such example would be the configuration of a titanium plate with semiconstrained screws. In this instance, the construct could have load-displacement responses different from a test coupon made of the same material. The end plate's configuration is essential in the test response and needs to be considered along with the material property referred to as modulus of elasticity. Although both are commonly referred to as "stiffness," a material's intrinsic property is different when configured as a medical device and loaded in FSU. All reflect a specific response given the same unit load, but loading conditions must be considered in the test protocols and the subsequent contextual stiffness definition.

Spinal interbody fusion devices have traditionally been designed and manufactured from homogenous materials. Examples include commercially pure titanium and titanium alloys. The device properties are dependent upon intrinsic material properties (e.g., modulus of elasticity or stiffness), whereas the implant construct exhibits design-dependent con- 


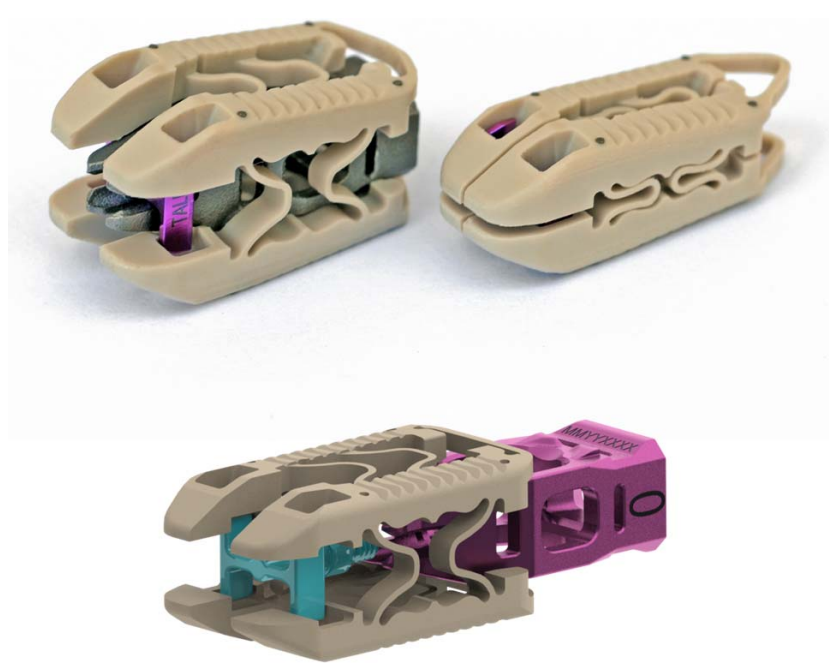

Figure. Example of a multimaterial, bidirectional expandable interbody device-FlareHawk.

struct stiffness along with those material properties. The rationale for polyetheretherketone (PEEK) interbody devices has primarily been based on the matched "stiffness" or modulus of elasticity between bone and PEEK. ${ }^{17}$ Clinically, the matched material stiffness and appropriate configuration of the interbody device design alleviated many of the original design problems with interbody cages that were overmatched in stiffness. ${ }^{18}$ Reducing the construct stiffness is essential, not only to reduce the risk of subsidence but also to increase the load sharing and improve bone formation as a function of Wolf law. An in vitro study conducted in 2018 by Peterson et $\mathrm{al}^{19}$ corroborated this relationship by showing that a more compliant anterior cervical discectomy and fusion construct resulted in increased load-sharing and reduced posterior element strain.

Multimaterial devices that can provide both flexibility and stability may have the potential to improve clinical outcomes by strategic implementation in design considering the intrinsic material stiffness for each component. This combination of materials and design strategies may result in devices with construct stiffness more favorable to load transfer between end plates. It also highlights the importance of considering stiffness in device design and interbody selection. When the modulus of elasticity of an interbody device is more than an order of magnitude higher than host bone and given the device design (e.g., wall thickness), complications may arise. ${ }^{20-22}$ Although devices manufactured from metals can have favorable bone apposition and remodeling characteristics, the dissimilarity between construct stiffness and the vertebrae's stiffness increases the risk of subsidence. In devices that incorporate different materials and more open geometries, an effective stiffness should be used to model the construct stiffness and generally include a "springs in series" type of stiffness model for a single device with multiple materials (Figure). Currently, titanium and PEEK polymer configurations fall into multimaterial device designs. In the case of numerous interbody devices, that is, 2 interbody cages with various design materials, the appropriate, effective stiffness could be modeled as springs parallel, with each spring modeled in series.

\section{THE PATIENT FACTOR}

Ideally, the final geometry of an interbody device would be a function not only of the device design but also conformation to each patient's unique disc space geometry. In those patients presenting with a "domelike" anatomy, the contact area between the device and endplate may be reduced and in turn increase the risk of subsidence. The effects of bone microstructure on cage subsidence have been studied, showing that bone volume fraction is the strongest predictor of subsidence and that endplate concavity ranges from 0.88 to $1.90 \mathrm{~mm}$ through the lumbar spine. ${ }^{23}$ A device that may be sufficiently compliant to conform to the space would theoretically reduce the risk of subsidence by increasing the contact area and in turn reducing the endplate stress. Initial radiographic outcome data can be used as an approximation for implant conformation by comparing medial and lateral dimensions. For example, if device height measurements taken in the medial aspect of the disc space are shown to be consistently higher than the height measurements taken at the lateral aspect of the disc space then implant deformation is likely-an observation that is described in a feasibility study reported by the same team of authors in this special IJSS focus issue on modern technology applications in minimally invasive spine surgery techniques.

\section{THE BURDEN OF PROOF}

Although the concept of the bidirectional expandable interbody device has been rationalized in support of fusion through a compliant shell that interfaces with the end plate and a titanium shim that provides structural support, clinical outcome studies will have to illustrate their clinical benefit in 
terms of improved patient self-reported outcome measures, lower complication and reoperation rates, as well as cost. The same team of authors of this editorial reported favorable clinical outcomes with bidirectionally expandable cages obtained in a feasibility study published in this IJSS focus issue. Results of the authors' deformation analysis show that the final device geometry is dictated by each patient's unique disc space geometry. In those patients presenting with "domelike" anatomy, the device may be sufficiently compliant to conform to the disc space. Deformation of a multimaterial bidirectional expandable interbody fusion cage design may increase the bone-implant interface's surface area and better distribute the load across the end plate. It may also contribute to sufficient stability of the FSU of the stabilized motion segment by providing a unique combination of compliant and rigid components to conform to the interbody space while maintaining stability necessary to achieve fusion. These concepts will have to be studied in conjunction with posterior supplement fixation, which is currently mandated by the regulator status of current multimaterial bidirectionally expandable cages. However, successful clinical applications of expandable interbody fusion cages without posterior supplemental pedicle-screw based instrumentation have been demonstrated by various authors. Expanded implementation of such expandable cages in outpatient spine care with simplified endoscopic and other forms of minimally invasive spinal surgeries may hinge on this bidirectional expandable technology's stand-alone application. The cost savings realized by hospitals and surgery centers with standalone versions of this technology may also impact its acceptance and rollout into the mainstream.

An implant with the ability to conform to the end plate represents a significant advancement. Chatham et $\mathrm{al}^{18}$ showed that custom interbody devices could reduce stress at the bone-implant interface by up to $37 \%$ and rod stress by $28 \%$. However, it is unclear whether this deformation results in a significant increase in the bone-implant interface's surface area because of the radiolucent nature of the PEEK components. As the number of devices featuring a combination of dissimilar materials and open geometries increases, the research surrounding how the construct stiffness of these devices influences arthrodesis should also be studied. Ideally, the configuration would allow a compliant or less stiff shell to cushion between a rigid inner core, much like the combination of PEEK and titanium, employed in contemporary design, such as the FlareHawk (Integrity Implants, Palm Beach Gardens, Florida). The rationale behind these composite implants is to produce an effective stiffness or a combined spring effect between PEEK and titanium to match the functional spinal unit's stiffness more appropriately.

\section{CONCLUSIONS}

The authors stipulate that interbody fusion devices with construct stiffness better matched to that of the patient's spinal motion segment will become more relevant in future clinical applications. The combination of components that are both compliant and structural may provide the anterior column support necessary to facilitate arthrodesis with the potential to reduce device-related complications, such as subsidence, migration, expulsion, and nonunion.

\section{REFERENCES}

1. Coric D, Branch CL. Posterior lumbar interbody fusion in the treatment of symptomatic spinal stenosis. Neurosurg Focus. 1997;3(2):e5. doi:10.3171/foc.1997.3.2.11

2. Closkey RF, Parsons JR, Lee CK, Blacksin MF, Zimmerman MC. Mechanics of interbody spinal fusion: analysis of critical bone graft area. Spine. 1993;18(8):10111015. doi:10.1097/00007632-199306150-00010

3. Cripton PA, Jain GM, RWittenberg RH, Nolte LP. Loadsharing characteristics of stabilized lumbar spine segments. Spine. 2000;25(2):170-179.

4. Pourtaheri S, Issa K, Lord E, et al. Paraspinal muscle atrophy after lumbar spine surgery. Orthopedics. 2016;39(2):209-214. doi:10.3928/01477447-20160129-07

5. Ge DH, Stekas ND, Varlotta CG, et al. Comparative analysis of two transforaminal lumbar interbody fusion techniques: open TLIF Versus Wiltse MIS TLIF. Spine (Phila Pa 1976). 2019;44(9):E555-E560 doi:10.1097/BRS. 0000000000002903

6. Zhao Y, Liang Y, Mao K. Radiographic and clinical outcomes following MIS-TLIF in patients with adult lumbar degenerative scoliosis. J Orthop Surg Res. 2018;13(1):93. doi:10. 1186/s13018-018-0764-7

7. Cao Y, Liu F, Wan S, et al. Biomechanical evaluation of different surgical procedures in single-level transforaminal lumbar interbody fusion in vitro. Clin Biomech (Bristol, Avon). 2017;49:91-95. doi:10.1016/j.clinbiomech.2017.08.011

8. Wilke HJ, Wenger K, Claes L. Testing criteria for spinal implants: recommendations for the standardization of in vitro stability testing of spinal implants. Eur Spine J. 1998;7(2):148154.

9. Newell N, Little JP, Christou A, Adams MA, Adam CJ, Masouros SD. Biomechanics of the human intervertebral disc: a 
review of testing techniques and results. $J$ Mech Behav Biomed Mater. 2017;69:420-34 doi:10.1016/j.jmbbm.2017.01.037

10. Gay RE, Ilharreborde B, Zhao K, Zhao CA, An KN. Sagittal plane motion in the human lumbar spine: comparison of the in vitro Quasistatic Neutral Zone and DynamicMotion parameters. Clin Biomech (Bristol, Avon). 2006;21(9):914-919.

11. Phillips FM, Tzermiadianos MN, Voronov LI, et al. Effect of the total facet arthroplasty system after complete laminectomy-facetectomy on the biomechanics of implanted and adjacent segments. Spine J. 2009;9(1):96-102.

12. Pflugmacher R, Schleicher $\mathrm{P}$, Gumnior $\mathrm{S}$, et al. Biomechanical comparison of bioabsorbable cervical spine interbody fusion cages. Spine. 2004;26(16):1717-1722.

13. Pflugmacher R, Schleicher $\mathrm{P}$, Schaefer $\mathrm{J}$, et al. Biomechanical comparison of expandable cages for vertebral body replacement in the thoracolumbar spine. Spine. 2004;29(13):1413-1419.

14. Cheng L, Yu Y, Zhu R, et al. Structural stability of different reconstruction techniques following total sacrectomy: a biomechanical study. Clin Biomech (Bristol, Avon). 2011;26(10):977-981.

15. Lee MJ, Bransford RJ, Bellabarba C, et al. The effect of bilateral laminotomy versus laminectomy on the motion and stiffness of the human lumbar spine: a biomechanical comparison. Spine. 2010;35(19):1789-1793.

16. Smolders LA, Kingma I, Bergknut N, et al. Biomechanical assessment of the effects of decompressive surgery in nonchondrodystrophic and chondrodystrophic canine multisegmented lumbar spines. Eur Spine J. 2012;21(9):1692-1699.

17. Noordhoek I, Koning MT, Jacobs WCH, VleggeertLankamp CLA. Incidence and clinical relevance of cage subsidence in anterior cervical discectomy and fusion: a systematic review. Acta Neurochir (Wien). 2018;160(4):873880. doi:10.1007/s00701-018-3490-3

18. Chatham LS, Patel VV, Yakacki CM, Dana Carpenter R. Interbody spacer material properties and design conformity for reducing subsidence during lumbar interbody fusion. $J$ Biomech Eng. 2017;139(5): 0510051-0510058. doi:10.1115/1. 4036312

19. Peterson JM, Chlebek C, Clough AM, Wells AK, Ledet
EH. Stiffness matters, part I: the effects of plate stiffness on the biomechanics of ACDF in vitro. Spine (Phila Pa 1976). 2018;43(18):E1061-E1068 doi:10.1097/BRS.0000000000002643

20. Seaman S, Kerezoudis P, Bydon M, Torner JC, Hitchon PW. Titanium vs. polyetheretherketone (PEEK) interbody fusion: meta-analysis and review of the literature. $J$ Clin Neurosci. 2017;44:23-29. doi:10.1016/j.jocn.2017.06.062

21. Jain S, Eltorai AE, Ruttiman R, Daniels AH. Advances in spinal interbody cages. Orthop Surg. 2016;8(3):278-284. doi:10.1111/os.12264

22. Xu J, He Y, Li Y, et al. Incidence of subsidence of seven intervertebral devices in anterior cervical discectomy and fusion: a network meta-analysis. World Neurosurg. 2020;141:479-489.e4. doi:10.1016/j.wneu.2020.03.130

23. Palepu V, Helgeson M, Molyneaux-Francis M, Nagaraja $\mathrm{S}$. The effects of bone microstructure on subsidence risk for ALIF, LLIF, PLIF, and TLIF spine cages. J Biomech Eng. 2018. doi:10.1115/1.4042181

Disclosures and COI: R.Y. is an employee of a device company; L.F. received funding from a device company; and D.C. served as a consultant and receives royalties from a device company. The other authors received no funding for this study and report no conflicts of interest.

Corresponding Author: Boyle Cheng, $\mathrm{PhD}$, 320 East North Ave, Suite 311, Pittsburgh, PA 15212. Phone: (412) 359-4020; Fax: (412) 359-4811; Email: Boyle.Cheng@ahn.org.

Published 9 December 2020

This manuscript is generously published free of charge by ISASS, the International Society for the Advancement of Spine Surgery. Copyright (c) 2020 ISASS. To see more or order reprints or permissions, see http://ijssurgery.com. 